\title{
OPPOSITIONAL REPRESENTATION OF DERIVATIONAL RELATIONS: A METALANGUAGE POTENTIAL
}

\author{
Aleksandr A. Barkovich \\ Belarusian State University, Minsk, Belarus
}

\begin{abstract}
The theoretical problem of language meta-description is considered with the support of oppositionality concept - an important feature of language system-forming relations. Oppositionality is a key characteristic of wide range of language relations, including derivational ones, which determine the identity of language dynamics. Opposition character of derivational relations is conditioned by their motivation and productivity. The importance of oppositionality in derivational processes allows the author of the article to qualify it as essential and promising basis for complex metalanguage descriptions. Particular attention is paid to the representation of language system modification capabilities in the morphological aspect, since this aspect of derivation problem domain is characterized by a significant potential of metalanguage representation. Verification and correct systematization of derivation term system has a priority in the modeling of referential language relations. The author has established that on the basis of consistent representation of basic derivational relations - in particular on the level of derivatemes, grammemes and flexionemes - a consistent development of the complex hierarchical meta-model of derivation is possible. It is shown that computer-mediated discourse provides a special urgency for such simulation as the actively developing communication phenomenon, which creates meanwhile a new quality of metalanguage practice. The base of modern speech practice - the statistical model of communication - determines the special relevance of formal criteria and parameters for the meta-description of single semantic continuum of language.

Key words: derivation, oppositionality, metalanguage, meta-description, hierarchical meta-model of derivation, derivateme, grammeme, flexioneme.

Citation. Barkovich A.A. Oppositional Representation of Derivational Relations: a Metalanguage Potential. Vestnik Volgogradskogo gosudarstvennogo universiteta. Seriya 2, Yazykoznanie [Science Journal of Volgograd State University. Linguistics], 2017, vol. 16, no. 4, pp. 255-264. (in Russian). DOI: https://doi.org/10.15688/ jvolsu2.2017.4.25
\end{abstract}

УДК 81:004.435

Дата поступления статьи: 30.06.2017

ББК 81.053 .2

Дата принятия статьи: 29.08.2017

\section{ОППОЗИЦИОННАЯ РЕПРЕЗЕНТАЦИЯ ДЕРИВАЦИОННЫХ ОТНОШЕНИЙ: МЕТАЯЗЫКОВОЙ ПОТЕНЦИАЛ}

\author{
Александр Аркадьевич Баркович \\ Белорусский государственный университет, г. Минск, Беларусь
}

\begin{abstract}
Аннотация. Теоретическая проблема метаописания языка рассматривается с опорой на понятие оппозиционности, отражающее важную черту системообразующих отношений языка, в том числе деривационных, определяющих идентичность динамики языка. Оппозиционный характер деривационных отношений обусловлен их мотивированностью и результативностью. Значимость оппозиционности в деривационных процессах позволяет автору статьи квалифицировать ее как существенное и перспективное основание комплексных метаязыковых описаний. Особое внимание уделено репрезентации модификационных возможностей языковой системы в морфологическом аспекте, поскольку данный аспект проблемной области деривации характеризуется существенным потенциалом метаязыковой репрезентации. При跎 оритетом в моделировании референтных языковых отношений является верификация и корректная систе(?) матизация деривационной терминосистемы. Автором установлено, что на основе непротиворечивой реп-
\end{abstract}


резентации базовых деривационных отношений - в частности на уровне дериватем, граммем и флексионем - возможно последовательное развитие комплексной иерархической метамодели деривации. Показано, что особую актуальность подобного моделирования обеспечивает компьютерно-опосредованный дискурс как активно развивающийся коммуникационный феномен, создающий при этом и новое качество метаязыковой практики. База современной речевой практики - статистическая модель коммуникации обусловливает высокую востребованность формальных критериев и параметров метаописания единого семантического континуума языка.

Ключевые слова: деривация, оппозиционность, метаязык, метаописание, иерархическая метамодель деривации, дериватема, граммема, флексионема.

Цитирование. Баркович А.А. Оппозиционная репрезентация деривационных отношений: метаязыковой потенциал // Вестник Волгоградского государственного университета. Серия 2, Языкознание. - 2017. T. 16, № 4. - C. 255-264. - DOI: https://doi.org/10.15688/jvolsu2.2017.4.25

\section{Введение}

Репрезентация деривационных закономерностей развития языка - одна из наиболее практически обусловленных лингвистических задач. Стратегической целью в метаязыковом плане является создание фреймовой инфраструктуры деривации как феномена. Несомненным приоритетом здесь будет оппозиционное моделирование, учитывающее специфику современного -компьютерно-опосредованного - формата речевой практики. Такое моделирование невозможно без устранения множественности в понимании и использовании важнейшего метаязыкового ресурса терминологического. Актуализация существенного потенциала лингвистической репрезентации референтной специфики и явилась объектом данного исследования.

\section{Современная обусловленность языкового моделирования}

С появлением компьютеров эмпирическая обеспеченность лингвистики существенно улучшилась, и по мере развития коммуникационных технологий дискурс в «электронном» формате становится все более репрезентативным [Баркович, 2015а]. Неудивительно, что сегодня новые количество и качество доступной для исследований речевой практики обусловливают сдвиг фокуса метаязыковых исследований в сферу металингвистики, по-новому актуализируя проблематику многоуровневой репрезентации языковой системы [Баркович, 2015б, с. 47]. Разумеется, сегодня, как и прежде, языковая система - абстракция, обеспеченная метаязыком и его воз- можностями «сопоставлять языковые знаки и говорить о самом языке», быть «структурным образованием» [Якобсон, 1985, с. 316]. При этом с учетом современной эмпирической обеспеченности лингвистики нередко поновому актуализируются «классические» метаязыковые описания. Примером такой традиционной для языкознания проблемной области, по-прежнему обладающей существенным потенциалом метаязыкового развития, является деривация - воплощенная в речевой деятельности вариативность единиц языка, в первую очередь, слов. В деривационном процессе имеет место «особая форма функционирования слова (функционирования с модификацией)» [Голев, 1989, с. 3].

Влиятельные функциональные реалии современной речевой деятельности - это и сам компьютерно-опосредованный дискурс (КОД) как активно развивающийся феномен, и его оппозиционная (бинарная) специфика. В данной связи оказывается особенно востребованной такое «... иерархическое и оппозиционное - в идеале, бинарное - метаязыковое обобщение, отражающее динамику деривационных отношений в речевой практике, как иерархическая метамодель деривации» [Баркович, 2017, с. 108]. Иерархическая логика заложена в концептуальной организации любого фрейма как такового: «... структура фрейма складывается по принципу схожести элементов и их связей с подчинительной связью общего и частного» [Балакин, 2015, с. 53]. Метамодель (как модель или совокупность моделей) позволяет объединять разнородные, непрямо связанные иерархические конструкции, например разноуровневые субмодели. Соответствующая репрезентация позволяет 
создавать динамические метаописания, стремящиеся к дискретности, но, ввиду сложности, не полностью структурированные подчинительными связями между элементами.

Преимущества обобщенной репрезентации деривационного измерения языка в виде модели очевидны. Это необходимо, в частности, для сущностного представления такого сложноорганизованного континуума, как единое семантическое поле языка. В КОД его функциональная динамика обусловлена совместимостью со статистической моделью коммуникации. Статистическая модель коммуникации - основанная на бинарных отношениях формально-языковая репрезентация языковых единиц. Такого рода репрезентация содержания (например, алгоритмы на основе простейшей альтернативы «0/1») обеспечивает максимально возможную дискретность метаописания. Именно эта модель детерминирует функциональность значимости, в том числе морфологической (грамматической), в КОД. Подобной модели соответствует принципиальная дифференциация конструктов деривационных отношений.

Традиционно метаописание языковой динамики ассоциируется с вполне определенной сложностью корректной интерпретации: «Динамическая модель размывает границу между нормой и инновациями (которая - предел - доставляет столько хлопот составителям словарей)» [Падучева, 2004, с. 16]. Однако описывать динамические и функциональные особенности речевой практики необходимо, и при всей подвижности КОД именно компьютерное обеспечение создает прозрачность процессов языковой системы, в том числе процесса деривации. Пожалуй, именно в деривационном аспекте динамика языка может быть охарактеризована последовательно и убедительно: не только как констатация «порождения» и «преобразования» отдельных номинативных единиц, но и как непрерывный процесс с присущими ему закономерностями, или «моделями» производство «из языковых строевых материалов по языковым моделям до известной степени аутентичных конструкций натуральной речи» [Адливанкин, Мурзин, 1984, с. 10].

Для объективной репрезентации КОД важны все элементы инфраструктуры рефе- рентных отношений: компьютерные программы могут обрабатывать открытые совокупности, «нечеткие множества» единиц, но эти единицы должны быть формально представленными. Следовательно, типологически и стереотипно идентичная словоизменительнословообразовательная - деривационная - общность языковых единиц может быть рассмотрена в таком контексте и соотнесена с матрицей речевого функционирования «статистического» типа.

Формализация естественного языка изначально оказалась ключевой проблемой совершенствования КОД. Вместе с тем уже при первых попытках объективно соотнести парадигматику языка со сферой его функционирования лингвисты столкнулись с существенными сложностями. Так, классикой русистики стали попытки вписать в формальные параметры падежную парадигму имен. В частности, наблюдения А.А. Зализняка над динамикой русской речи послужили аргументом для предложений по существенной модификации падежной модели: «Формально все имена признаются имеющими единую 14-падежную систему» [Зализняк, 2002, с. 54]. Зализняк выделил четыре родительных падежа, по два дательных, винительных, творительных, предложных, наряду с именительным падежом и счетной формой [Зализняк, 2002, с. 53]. Модель «14-падежной системы» оказалась слишком революционной для русской лингвистики, и на практике, в согласованном научном сопровождении дискурса, так и не нашла воплощения. Однако в «Национальном корпусе русского языка» уже реализована 11-падежная словоизменительная модель (Национальный корпус русского языка. URL: http://www.ruscorpora.ru).

Итак, метаязыковое решение любых масштабных проблем в условиях современной чрезвычайно экстенсивной речевой практики нереально найти вне методики моделирования. Модель - стабильная обобщенная репрезентация, отражающая идентичность предмета метаописания, - актуальнейший ресурс описания языка. Само метаописание «... подразумевает репрезентацию объекта в контексте и средствами вторичной семиотической либо абстрактной системы» [Баркович, 2016, с. 10-11]. Подобные обобщения с помощью оппозиционного моделирования могут 
быть сделаны и применительно к сфере модификационного развития важнейшего «измерения» языка - деривации. Дискурсивная идентичность таких обобщений позволяет квалифицировать их вполне определенную инновационность, в частности в рамках дискурсивного моделирования - создания и развития дискурсивно-релевантных моделей коммуникации как отдельных текстовых фрагментов, так и речевой деятельности в самом широком контексте. При этом дискурсивное моделирование практически любого аспекта языковых отношений, в том числе деривационного, очевидным образом «... целесообразно для совершенствования современной коммуникации» [Баркович, 2017, с. 116].

\section{Метаязыковая специфика оппозиционности}

Метаязыковая специфика деривационных отношений контрастна при противопоставлении производящих единиц производным, мотивирующих - мотивированным, обусловливающих единиц - обусловленным, источников деривации - ее результатам и т. д. Подобные отношения продуктивно рассматривать через призму оппозиционности - противоположности, противопоставления двух и более объектов на основании существенного для них признака. Актуализация тех или иных языковых единиц в речи во многом подкреплена их оппозиционным потенциалом на морфологическом уровне. Так, показательна функциональность деривационной составляющей оппозиций, подобных диадам коммуникациионный - коммуникативный, номинационный - номинативный и др. Их существование было бы бессмысленным (и нереализованным) в речевой практике, если бы развитие подобных вариантов не диктовалось потребностями языка в функциональной дифференциации референтных значений [Баркович, 2015б].

Оппозиционность - важная черта целого ряда системообразующих отношений в языке: «каждая единица системы определяется ... совокупностью отношений к другим единицам и оппозиций, в которые она входит; единица есть явление относительное и оппозиционное, как говорил Соссюр. Мы отказы- ваемся, таким образом, от мысли, что каждый “факт” языка можно расценивать сам по себе, что он является абсолютной и объективной величиной, которая допускает изолированное рассмотрение» [Бенвенист, 1974, c. 24]. Разного рода противопоставления одна из основных гносеологических методик, ее самой известной принципиальной реализацией в лингвистике является понятие дихотомии, например, язык - речь.

Афоризм Ф. де Соссюра «в языке нет ничего кроме различий» объективно описывает практику метаязыковой интерпретации оппозиционных отношений языковой системы [Соссюр, 1977, с. 152]. В контексте КОД вопрос о степени синонимичности терминов бинарность и оппозищия оказывается принципиально важным. В данных условиях методика противопоставления имеет безусловный приоритет и полезность уже по причине статистического формата соответствующей коммуникационной модели. Безальтернативный бинарный принцип - фундаментальное основание КОД.

Семантика оппозиционности тесно коррелирует с бинарностью: в широком контексте оба термина можно рассматривать как синонимические. Вместе с тем очевидна некоторая гиперонимичность термина оппозииионность (чаще - оппозиция) по отношению к термину бинарность. Предпочтительность терминологической парадигмы «оппозиционности» в прикладной лингвистике обусловлена ее более широким понятийным потенциалом: равноценных противопоставлений может быть более чем одно - бинарное.

Несмотря на бинарную природу любого противопоставления, характеристики оппозиционности позволяют рассматривать языковые отношения, в том числе деривационные, в широком контексте, с учетом их градуальности и динамики. Важность бинарных признаков, бинарной шкалы отмечал, например, Ю.Д. Апресян [Апресян, 1995, с. 294]. При этом концепция «шкалы неоднозначности» в языковых отношениях подразумевает скорее их оппозиционность: «...семантические поля по сути классы пересекающиеся; единого разбиения словаря на семантические поля, если не принимать искусственных принципов классификации и не подменять семантические ком- 
поненты бинарными или иными дифференциальными признаками, не существует; из любого семантического поля, через более или менее длинную цепочку посредствующих звеньев, можно попасть в любое другое поле, так что семантическое пространство языка оказывается в этом смысле непрерывным» [Апресян, 1995, с. 252].

Метаязыковая рефлексия семантики бuнарности - оппозиционности характеризуется рядом особенностей.

1. Презентации бинарности нет в части словарей лингвистических терминов, например у Ж. Марузо, Д.Э. Розенталя и М.А. Теленковой, Т.В. Жеребило и др. [Жеребило, 2010; Марузо, 1960; Розенталь, Теленкова, 1976].

2. Презентация бинарности в «Словаре лингвистических терминов» О.С. Ахмановой отсылает к семантике единицы бинарный: «1. Составленный из двух частей, имеющий две составляющих (англ. constituents). 2. Исходящий из двучленности как обязательного (конституирующего) свойства изучаемого лингвистического объекта и, следовательно, методологической основы его исследования и описания. Бинарный принцип (дихотомический принцип) англ. binary principle. Принцип описания языковых систем, основанный на предположении, что фонологическая - и даже морфологическая - система каждого языка поддается сведению к ограниченному числу бинарных оппозиций. Бинарное противопоставление $c$. противопоставление» [Ахманова, 1966, с. 64].

3. Как и бинарность, оппозиция в словаре О.С. Ахмановой характеризуется с помощью семантики противопоставления: «ОППОЗИЦИЯ. То же, что противопоставление» [Ахманова, 1966, с. 289]. Объемная статья данного словаря «Противопоставление» дифференцирует понятие на отдельные значимости: противопоставление антитезное, противопоставление билатеральное, противопоставление бинарное, противопоставление градуальное, противопоставление дифференциальное, противопоставление изолированное, противопоставление количественное, противопоставление константное, противопоставление многостороннее, противопоставление морфологическое, противопоставление привативное, противопоставление пропорииональное, противопоставление фонологическое, противопоставление эквиполентное. Дополнительно в статье описывается возможная элементная структура оппозиции, включающая внешний член противопоставления, крайний член противопоставления, средний член противопоставления, и характер системных связей - противопоставление фонологическое косвенное, противопоставление фонологическое прямое, противопоставления фонологической основы [Ахманова, 1966, с. 360].

4. Металингвистические толкования onпозищии (противопоставления) традиционно связаны с фонологией, либо прямо апеллируя к ней («одна из комплексных единиц системы фонем, фонемная группа» [Жеребило, 2010]), либо косвенно ссылаясь на примеры («противопоставление двух или нескольких однородных единиц языка, проводимое для выявления различий между ними. Оппозищия лабиализованных и нелабиализованных гласных. Оппозииия глухих и звонких согласных» [Марузо, 1960; Розенталь и др., 1976]). Морфологические оппозиции упоминаются в лексикографическом контексте противопоставления, оппозиции факультативно [Ахманова, 1966; Жеребило, 2010].

Итак, лингвистическая презентация оппозиционных отношений имеет весьма избирательный характер. Для фонетического уровня минимальная по языковым меркам значимость признана релевантной оппозиционным отношениям, но более сложные языковые уровни не обещают реальных успехов в систематизации оппозиционной значимости. Хотя отдельные попытки ситематизации лексических и грамматических (главным образом, морфологических) оппозиций предпринимались (компонентный анализ, анализ по непосредственным составляющим и др.), говорить о создании общепризнанных теорий и методологий на фундаменте оппозиционных отношений - выше фонетического уровня - пока не приходится. Значение же комплексной многоуровневой презентации оппозиционной значимости сложно переоценить: «беспримерная эффективность языка коренится в последовательном наложении нескольких взаимосвязанных уровней, каждый из которых особым об- 
разом структурирован» [Якобсон, 1985, с. 314]. Сложность описания, например, морфологического уровня оппозиционных отношений $\mathrm{P}$. Якобсону была очевидна: «Однако здесь мы сталкиваемся с существенным различием между фонологической и грамматической оппозицией: в первом случае связанные друг с другом противоположности располагаются в плоскости восприятия языка (signans, или «о3начающее»), тогда как во втором случае такие противоположности лежат в плоскости понимания языка (signatum, или «означаемое») [Якобсон, 1985, с. 314].

\section{Потенциал моделирования деривационных отношений}

Обоснованность исследований структуры языковых отношений подтверждается обширной лингвистической практикой [см. например, Баркович, 2015в]. Уместность оппозиционного метаописания в контексте деривационной проблематики подтверждается закреплением в метаязыковых описаниях таких концептуальных номинаций, как дериватема, граммема и флексионема.

Несмотря на более чем полувековую историю термина граммема, он остается не особенно востребованным и дискуссионным. Одним из первых среди российских лингвистов на него обратил внимание А.А. Зализняк: «Граммемой мы будем называть всякий отдельный грамматический элемент значения, для которого не нашлось сопряженного с ним грамматического же элемента, a также всякую пару сопряженных между собой грамматических элементов. Совокупность всех однородных между собой граммем называется грамматической категорией. Примеры грамматических категорий: число (как обозначение совокупности граммем «ед. число» и «мн. число»), падеж, род и т. д.» [Зализняк, 2002, с. 27].

Недостаточность такой констатации оппозиционного потенциала грамматических отношений была очевидной И.А. Мельчуку, который не только творчески интерпретировал термин граммема в контексте метаязыковых исследований, но и дополнил характеристику оппозиционных отношений термином дериватема. Значимость дериватемь
Мельчук объяснил именно через ее противопоставление граммеме:

Граммемы имеют тенденцию:

1) быть абстрактными;

2) иметь относительно широкую сочетаемость;

3) иметь стандартные средства выражения; вилах;

4) фигурировать в синтаксических пра-

5) избегать амальгамирования с лексическими значениями;

6) выражаться показателями, которые располагаются дальше от корня, чем показатели дериватем;

7) не изменять частеречность исходной основы [Мельчук, 1997, с. 282].

Дериватемы имеют тенденцию:

1) быть определенными;

2) иметь относительно ограниченную сочетаемость;

3) иметь нестандартные средства выражения;

4) оставаться вне сферы действия синтаксических правил;

5) допускать амальгамирование с лексическими значениями;

6) выражаться показателями, которые располагаются ближе к корню, чем показатели граммем;

7) изменять частеречность исходной основы [Мельчук, 1997, с. 282].

Существенным свойством дериватемы И.А. Мельчук признал то, что «дериватемы различают разные лексемы» [Мельчук, 1997, c. 284]. Среди русскоязычных иллюстраций граммемно-дериватемной оппозиции Мельчук предоставил такой пример: «В русском языке работа + em + ся [как], где работа - это основа, -еm - окончание 3-го лица в настоящем времени (граммема - А.Б.), а -ся - возвратный суффикс, который служит для образования одного глагола от другого со значением 'процесс $X$-а идет $Y$-ово' (дериватема A.Б.)» [Мельчук, 1997, с. 281]. Вместе с тем корреляция значения дериватемы со словообразовательным аспектом деривации, а граммемы - со словоизменительным нельзя назвать полностью прозрачным в металингвистическом плане. Сам Мельчук, понимая некоторую семантическую противоречивость созданной им оппозиционной модели, и пред- 
ложил называть граммемы «флексионемами»: «Логически более последовательно было бы ввести термин флексионема для значений словоизменительных категорий и употреблять термин граммема для совокупности флексионем и дериватем. Мы, однако, не решились слишком резко нарушить традицию» [Мельчук, 1997, с. 251].

Не до конца сформированная «традиция» «оппозиционной» терминосистемы деривации с точки зрения семантики когерентных понятий может быть представлена и более последовательно - в рамках иерархической метамодели деривации, функциональной в морфологическом контексте. Ключевым средством (компонентом) референтного структурирования на морфологическом уровне является конcmpукm - важный элемент концептуальной инфраструктуры дискурса - метаязыковая субмодель синтетического, созидательного качества; абстрактный элемент системы, но взаимосвязанный, соотносимый и совместимый с другими элементами. В таком ракурсе дериватема - это языковая единица, обобщенная совокупность словообразовательных и словоизменительных конструктов; парадигматическое средство, которое, как правило, на регулярной основе реализует оппозиционную специфику словообразовательного или словоизменительного типа. Соответственно, граммема - это языковая единица, словообразовательный конструкт; парадигматическое средство, которое на регулярной основе реализует оппозиционную специфику словообразовательного типа, а флексионема - это языковая единица, словоизменительный конструкт; парадигматическое средство, которое, как правило, на регулярной основе реализует оппозиционную специфику словоизменительного типа. Такая репрезентация релевантна моделированию оппозиционной специфики деривационного измерения языка. Системообразующими элементами субмодели на морфологическом уровне оказываются гипероним дериватема и оппозиционные гипонимы граммема и флексионема.

Металингвистическая интерпретация типичных вариантов деривационных отношений позволяет существенно уточнить характеристику совокупностей-классов языковых единиц - деривационных категорий. Об оп- позиционной структурированности модификационной динамики языка говорит, в частности, Мельчук: «Категорией называется максимальное множество значений, которые исключают друг друга в одной и той же позиции (семантической или логической)» [Мельчук, 1997, с. 247]. Характерным в рассуждениях И.А. Мельчука является стремление максимально четко определить идентичность деривационных закономерностей через анализ взаимоисключающих «позиций» - оппозиций, по сути.

В современных условиях востребованность работоспособных моделей речевой практики постоянно возрастает: «при всей значимости для современной лингвистической парадигмы эмпирических данных развитие лингвистики как науки не может не сопровождаться систематизацией и обобщением первичных данных, их моделированием на уровне метаописаний, практикой репрезентации и интерпретации обобщений» [Баркович, 2016, c. 11]. Деривационная специфика - один из потенциально продуктивных аспектов изучения языковой динамики, а доминирующий сегодня компьютерно-опосредованный контекст речевой деятельности делает такое изучение весьма актуальным.

Необходимость рассмотрения языковых фактов в контексте компьютерного опосредования современной речевой практики обусловлена характером презентации в ней языковых данных. Компьютерно-опосредованная коммуникация - интерактивное взаимодействие коммуникационных субъектов в опосредованной компьютерными технологиями среде речевой практики - обеспечивает почти неограниченную эмпирическую базу и высокое качество ее первичных обобщений, что востребовано в широком метаязыковом контексте [Баркович, 2015а]. Использование таких обобщений обладает существенным потенциалом их интеграции в современные представления об особенностях языковой системы, нередко создавая предпосылки для их коррекции. Научная убедительность подобной практики обеспечена активным использованием метаязыковых обобщений и моделей в рамках, в частности, развития компьютерных технологий, изначально базирующихся на программах - формально-языковых текстах. 
Релевантное моделирование предполагает корреляцию метаязыковой практики с оппозиционной спецификой современной речевой деятельности. Оппозиционность - сущностная характеристика КОД, обусловленная «статистической моделью» соответствующего типа коммуникации. Такая специфика налагает определенные ограничения на возможности отражения значимости в речевой практике, в частности предполагает иерархическую организацию метаописаний. Однако в КОД имеются и дополнительные (в частности, статистические) возможности по репрезентации важнейших аспектов функционирования языка, в том числе деривационного. В контексте метаязыковой интерпретации КОД характеризуется существенной идентичностью и релевантностью для экспликации и интерпретации моделей деривационных отношений. Использование возможностей КОД в лингвистической практике оказывается все более востребованным и результативным, с одной стороны, и предъявляет вполне определенные требования к метаязыковому инструментарию, с другой стороны.

\section{Выводы}

Системный характер оппозиционных отношений в деривационных процессах позволяет квалифицировать их как существенные и перспективные в контексте создания метаязыковых описаний. Разумеется, вторичность и зависимость деривационной дедукции от специфики отраженной в дискурсе вариативности языковой системы вполне очевидна, однако это не исключает ее влияния на складывающиеся стереотипы языкознания и их обоснованную коррекцию. Важным в данном контексте является непротиворечивая интерпретация деривационной терминосистемы, в частности последовательная и обоснованная актуализация таких базовых терминов, как дериватема, граммема, флексионема. Раскрытие сущностного и функционального потенциала языковых отношений в метаязыковом аспекте позволяет более полно использовать возможности статистической модели современной коммуникации - как при описании актуальных моделей языкового инструментария, так и при моделировании языковых систем.
Создание языкового фрейма - структурированного метаописания - характеризуется высокой степенью практической целесообразности в самом широком контексте. Одним из оснований такого фрейма может быть иерархическая метамодель деривации. При всей гибкости современной лингвистики в методологическом плане ее категориальный аппарат сохранен практически в неизменном виде со времен Ф. де Соссюра. Интерпретация статистически репрезентативного речевого материала позволяет развивать верифицированные металингвистические описания на качественно новом уровне - с учетом сегодняшних практически безграничных возможностей по агрегированию языковых данных.

\section{СПИСОК ЛИТЕРАТУРЫ}

Адливанкин С. Ю., Мурзин Л. Н., 1984. О предмете и задачах дериватологии // Деривация и текст: межвуз. сб. науч. тр. Пермь : Изд-во Пермского ун-та. С. 3-12.

Апресян Ю. Д., 1995. Избранные труды : в 2 т. Т. 1. Лексическая семантика: Синонимические средства языка. М. : Языки русской культуры. 472 с.

Ахманова О. С., 1966. Словарь лингвистических терминов. М. : Сов. энцикл. 607 с.

Балакин С. В., 2015. Концептуальная система русского, французского и португальского языков: деривационный потенциал. Екатеринбург : УрГУПС. $191 \mathrm{c.}$

Баркович А. А., 2015а. Интернет-дискурс: компьютерно-опосредованная коммуникация. М. : Флинта : Наука. 288 с.

Баркович А. А., 2015б. Функциональность диады «коммуникационный - коммуникативный»: дискурсивный аспект // Вестник Томского государственного университета. Филология. № 5(37). C. 37-52. DOI: 10.17223/19986645/37/3.

Баркович А. А., 2015в. Лингвоинформационная специфика компьютерно-опосредованной коммуникации: структурный аспект // Вестник Волгоградского государственного университета. Серия 2, Языкознание. Т. 14, № 2. C. 114-120. DOI: 10.15688/jvolsu2.2015.2.16.

Баркович А. А., 2016. Корпусная лингвистика: специфика современных метаописаний языка // Becтник Томского государственного университета. № 406. C. 5-13. DOI: 10.17223/15617793/406/1

Баркович А. А., 2017. Информационная лингвистика : Метаописания современной коммуникации. М. : Флинта : Наука. 360 с. 
Бенвенист Э., 1974. Общая лингвистика [пер. с франц.]. М. : Прогресс. 447 с.

Голев Н. Д., 1989. Динамический аспект лексической мотивации. Томск : Изд-во Том. ун-та. $252 \mathrm{c}$.

Жеребило Т. В., 2010. Словарь лингвистических терминов. Назрань : Пилигрим. 486 с.

Зализняк А. А., 2002. «Русское именное словоизменение» с приложением избранных работ по современному русскому языку и общему языкознанию. М. : Языки славянской культуры. 752 c.

Марузо Ж., 1960. Словарь лингвистических терминов. М. : Издательство иностранной литературы. 436 с.

Мельчук И. А., 1997. Курс общей морфологии. Том І. Введение. Часть первая: Слово. М. : Языки русской культуры. 416 с.

Падучева Е. В., 2004. Динамические модели в семантике лексики. М. : Яз. слав. культуры. 609 с.

Розенталь Д. Э., Теленкова М. А., 1976. Словарьсправочник лингвистических терминов. М. : Просвещение. 543 с.

Соссюр Ф. де, 1977. Курс общей лингвистики // Труды по языкознанию. М. : Прогресс. С. 31-273.

Якобсон Р., 1985. Речевая коммуникация //Избранные работы. М. : Прогресс. С. 306-318.

\section{REFERENCES}

Adlivankin S.Yu., Murzin L.N., 1984. On the subject and tasks of derivatology. Derivatsiya $i$ tekst: mezhvuz. sb. nauch. tr. Perm, Izd-vo Perm. gos. un-ta, pp. 3-12. (in Russian).

Apresyan Yu.D., 1995. Selected Works, in 2 vols. Vol. I.: Lexical semantics. Synonimic means of language. Moscow, Yazyki russkoy kulytury Publ. 472 p. (in Russian).

Akhmanova O.S., 1966. Dictionary of Linguistic Terms. Moscow, Sovetskaya entsiklopediya Publ. 607 p. (in Russian).

Balakin S.V., 2015. Conceptual system of the Russian, French and Portuguese languages: derivational potential. Ekaterinburg, USURT Publ. 191 p. (in Russian).

Barkovich A.A., 2015. Internet discourse: computermediated communication. Moscow, Flinta, Nauka Publ. 288 p. (in Russian).

Barkovich A.A., 2015. Functionality of the "communicational-communicative" Dyad: a Discursive Aspect. Vestnik Tomskogo gosudarstvennogo universiteta. Filologiya [Tomsk State University Journal of Philology], no. 5(37), pp. 37-52. DOI: 10.17223/19986645/37/ 3. (in Russian).

Barkovich A.A., 2015. Linguistic and informational specifics of computer-mediated communication: structural aspect. Vestnik Volgogradskogo gosudarstvennogo universiteta. Seriya 2. Yazykoznaniye [Science Journal of Volgograd State University. Linguistics], vol. 14, no. 2, pp. 114-120. DOI: http://dx.doi.org/10.15688/ jvolsu2.2015.2.16. (in Russian).

Barkovich A.A., 2016. Corpus Linguistics: the specificity of the language of modern meta descriptions. Vestnik Tomskogo gosudarstvennogo universiteta [Tomsk State University Journal], no 406, pp. 5-13. DOI: 10.17223/15617793/406/1. (in Russian).

Barkovich A.A., 2017. Informational linguistics: Metadescriptions of modern communication. Moscow, Flinta, Nauka Publ. 360 p. (in Russian).

Benveniste E., 1974. General linguistics. Moscow, Progress Publ. 447 p. (in Russian).

Golev N.D., 1989. The dynamic aspect of lexical motivation. Tomsk, Izd-vo Tom. un-ta. 252 p. (in Russian).

Zherebilo T.V., 2010. Dictionary of linguistic terms. Nazran', Piligrim, 2010. 486 p. (in Russian).

Zaliznjak A.A., 2002. "Russian nominal inflection" with the application of selected works by contemporary Russian language and general linguistics. Moscow, Jazyki slavyanskoy kul'tury. 752 p. (in Russian).

Maruzo Zh., 1960. Dictionary of linguistic terms. Moscow, Izd-vo inostrannoy literatury. $436 \mathrm{p}$. (in Russian).

Melchuk I.A., 1997. The course of the general morphology. Vol. I. Introduction. Part One: The word. Moscow, Yazyki russkoy kultury. $416 \mathrm{p}$. (in Russian).

Paducheva E.V., 2004. Dynamic models in the semantics of language. Moscow, Yazyki slavyanskoy kultury Publ. 609 p. (in Russian).

Rozental D.E., Telenkova M.A., 1976. Dictionaryreference book of linguistic terms. Moscow, Prosveshchenie Publ. 543 p. (in Russian).

Sossjur F. de, 1977. Course in General Linguistics. Trudy po yazykoznaniyu. Moscow, Progress Publ., pp. 31-273. (in Russian).

Jakobson R., 1985. Speech communication. Izbrannye raboty. Moscow, Progress Publ., pp. 306-318. (in Russian). 


\section{Information about the Author}

Aleksandr A. Barkovich, Doctor of Sciences (Philology), Associate Professor, Department of Applied Linguistics, Belarusian State University, K. Marksa St., 31, 220050 Minsk, Belarus, albark@tut.by, http://orcid.org/0000-0001-8469-8431

\section{Информация об авторе}

Александр Аркадьевич Баркович, доктор филологических наук, доцент, доцент кафедры прикладной лингвистики, Белорусский государственный университет, ул. К. Маркса, 31, 220050 г. Минск, Беларусь, albark@tut.by, http://orcid.org/0000-0001-8469-8431 